\title{
BALANCE DEL REFERENDO SOBRE EL TLC EN COSTA RICA A LA LUZ DE LA TEORÍA DE LA DEMOCRACIA ${ }^{1}$
}

\section{BALANCE OF THE REFERENDUM ON CAFTA IN COSTA RICA IN THE LIGHT OF DEMOCRATIC THEORY}

\section{Ciska Raventós*}

RESUMEN

En este artículo exploro el potencial democratizador de las instituciones de democracia directa a partir del análisis del referendo sobre el Tratado de Libre Comercio (CAFTA-DR) realizado en Costa Rica el 7 de octubre de 2007. En términos teóricos busco situar los aportes de la teoría de la democracia participativa para enriquecer la perspectiva de la democracia representativa. En términos empíricos, describo el diseño institucional así como las prácticas políticas en esta primera experiencia de consulta. Concluyo que el referendo evidenció un retroceso en términos de la legitimidad de la institucionalidad electoral, en tanto que supuso avances en la construcción de ciudadanía.

PALABRAS CLAVE: COSTA RICA * DEMOCRACIA * REFERÉNDUM * DEMOCRACIA REPRESENTATIVA $*$ DEMOCRACIA PARTICIPATIVA $*$ CIUDADANÍA

ABSTRACT

In this paper I explore the democratic potential of direct democracy, on the basis of a case study of the referendum on CAFTA that took place in Costa Rica on October 7, 2007. Theoretically, I aspire to show how developments in the field of participatory democracy can enrich the analysis of democratic regimes. Empirically, I describe the institutional design and political practices in this first experience. I conclude that the referendum entailed reversals in terms of electoral fairness and legitimacy, as well as progress in the construction of citizenship.

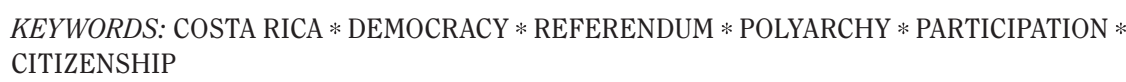

Instituto de Investigaciones Sociales de la Universidad de Costa Rica.

ciskar@yahoo.co.uk
$1 \quad$ Agradezco los agudos comentarios de Jeremy Rayner y Marco Fournier a versiones anteriores de este trabajo. 
PERSPECTIVA TEÓRICA: DEMOCRACIA DIRECTA: ¿PUENTE ENTRE LA TEORÍA DE LA DEMOCRACIA REPRESENTATIVA Y DE LA DEMOCRACIA PARTICIPATIVA ${ }^{2}$ ? UNA PERSPECTIVA ANALÍTICA Y NORMATIVA

En los últimos años, ha habido un proceso de expansión de las instituciones de democracia directa en América Latina y en el mundo. Existe debate sobre los efectos - positivos y negativos- que las consultas populares pueden tener sobre la democracia. Esta discusión se complica debido a la polisemia del concepto de democracia, que conduce a que las preguntas sean diferentes según la perspectiva teórica de quienes las hacen. Para quienes se sitúan dentro de los parámetros del pluralismo elitista competitivo (democracia representativa o liberal), la democracia es en lo fundamental un régimen político caracterizado por las elecciones para seleccionar a los gobernantes (representantes), donde los partidos políticos tienen el monopolio de la postulación de candidaturas. Estos pensadores y actores políticos se plantean las siguientes preguntas respecto de las instituciones de democracia directa: ¿Contribuyen los referendos al debilitamiento de los terrenos de mediación política donde se dan la deliberación $y$ negociación inter-partidaria? Y en este mismo sentido ¿Contribuyen al debilitamiento de los partidos? ¿Acentúan los rasgos plebiscitarios de tal forma que la consulta se convierte en una aprobación o rechazo del jefe de estado? ¿Contribuyen al fortalecimiento de liderazgos carismáticos? ¿Conducen las consultas a una excesiva participación que debilita la gobernabilidad? En general, sus preocupaciones son de tres tipos: (1) aquellas asociadas al debilitamiento de los terrenos de mediación, centrales para la construcción de la representación política, $y$ de forma estrechamente relacionada, (2) aquellas asociadas a la construcción de relaciones autoritarias entre líderes carismáticos y el pueblo movilizado y (3) al temor de una participación popular "excesiva"3.

2 La primera se sitúa dentro de la tradición liberal, mientras que la segunda es de inspiración republicana.

3 La desconfianza respecto de la participación popular, así como los temores con respecto de sus excesos
Para dimensionar los riesgos que pueden significar los ejercicios de democracia directa para las mediaciones de los regímenes democrático-representativos en América Latina, es necesario partir de las democracias "realmente existentes" y no del ideal de estas. Existe relativo consenso en la literatura referida a las democracias latinoamericanas respecto de la poca densidad y debilidad de los vínculos entre gobernantes y gobernados, de los amplios márgenes de discrecionalidad de los gobernantes y el peso de la influencia política del empresariado. O'Donnell (1994) ha acuñado el término "democracia delegativa" para destacar la debilidad del vínculo representativo en las democracias latinoamericanas, donde los ciudadanos eligen gobernantes que luego ejercen su mandato con un alto grado de autonomía y distancia de sus compromisos de campaña, de los congresos y de la sociedad civil. A esto se agregan las grandes limitaciones de la democracia interna de los partidos, $y$ la ausencia de mecanismos eficaces de rendición y petición de cuentas (Levitsky, Peruzotti). La insuficiente regulación del financiamiento de la política ha llevado a la colonización de los partidos y los gobiernos por parte de los intereses económicos (Zovatto y Orozco, 2008: 157-160; Zovatto, 1998). Como consecuencia, son regímenes donde las mediaciones son débiles y en los cuales se ha dado con frecuencia liderazgos carismáticos poco democráticos. Las inquietudes deben por tanto situarse en relación con la posibilidad de que las consultas populares pudieran debilitarlas aún más.

En contraposición a las preocupaciones por una excesiva participación que subyacen a la perspectiva liberal, lo que se ha dado en llamar la democracia participativa, celebra el establecimiento de instancias de participación de toma de decisiones, en la medida en que pueden

emergen del linaje liberal. El liberalismo no es democrático en sus orígenes y es sólo después de una larga historia de luchas y conflictos que surgen las concepciones democrático-liberales (Held, 1987:5). Subsiste por tanto en esta tradición un cierto prejuicio elitista a la participación que se expresa de alguna forma en las preocupaciones que enuncian. 
contribuir a desarrollar ciudadanía. Para los teóricos de esta vertiente el ciudadano "libre e igual" que postulan los liberales es una ficción dadas las asimetrías de poder y de recursos que existen en las sociedades contemporáneas. Las formas de democracia participativa contribuyen a la construcción de ciudadanía a través del involucramiento en los problemas colectivos que a su vez contribuyen al desarrollo de las personas, al aumento de la eficacia política y el empoderamiento, la reducción de la sensación de alienación de los centros de poder (Pateman, 1970; Held, 1987). Dentro de esta perspectiva, las instituciones de democracia directa podrían contribuir a la construcción de ciudadanía, al involucrar a las personas a la toma de decisiones sobre temas de interés colectivo y extender los procesos electorales más allá de la selección de candidatos. Los referendos podrían formar parte de una - entre muchas otras- oportunidades de construcción de ciudadanía.

Las experiencias de participación también pueden fortalecer las mediaciones entre políticos y ciudadanos. En una contribución reciente, Dagnino, Olvera y Panfichi sitúan el núcleo de su definición de lo que llaman el "proyecto democrático-participativo" precisamente en la construcción de nuevos y densos vínculos entre ciudadanos y el estado, entre gobernantes y gobernados (Dagnino; Olvera; Panfichi, 2006). Este proyecto se fundamenta

[en] la ampliación del concepto de política a través de la participación ciudadana y de la deliberación en los espacios públicos, de lo que se deriva una noción de democracia como un sistema articulado de instancias de intervención de los ciudadanos en las decisiones que les conciernen $y$ en la vigilancia del ejercicio del gobierno (p. 6).

En este artículo parto de la perspectiva de que las contribuciones teóricas de la democracia participativa le aportan a la teoría de la democracia liberal una mirada habitualmente ausente en los estudios que se enfocan de forma estrecha en las instituciones de la democracia representativa (partidos, parlamentos e instituciones electorales). El desarrollo de una ciudadanía activa puede ser precisamente el factor que presione para la formación de densos y complejos vínculos representativos y a establecer límites al poder discrecional de gobernantes $y$ tenedores del poder económico. La historia de la democracia corrobora esta tesis.

En segundo lugar, más allá de las diferencias conceptuales y normativas entre quienes entienden la democracia a partir del énfasis en la representación o de la participación política, postulo que son complementarias. Desafortunadamente, con frecuencia la relación entre defensores de una concepción de democracia participativa y de democracia representativa se plantea como un diálogo de sordos entre dos modelos que se visualizan como antagónicos y mutuamente excluyentes. Esta construcción del debate no es ni teórica, ni políticamente fecunda. Más aún, construye una falsa oposición, en la medida en que no es posible pensar en un régimen democrático al nivel del estado-nación moderno sin la existencia de mecanismos de representación política ${ }^{4}$ (independientemente de que sean o no "partidos" las organizaciones que construyen la representación y de las formas que asume la elección de los representantes). Por otra parte, si bien la democracia participativa contiene la promesa de "democratizar la democracia" 5 al construir ciudadanía a través de la deliberación, negociación y toma de decisiones colectivas, la mayor parte de las experiencias de participación exitosas se registran en el nivel de la política local. Su mayor debilidad, hasta ahora, reside en sus límites para incidir en la democratización del régimen político, para lo cual las instancias de mediación entre gobernantes y gobernados son cruciales.

El referendo, como institución que somete decisiones públicas importantes a consulta ciudadana, puede ser sitio de encuentro entre la democracia representativa $y$ la democracia

Esta posición es asumida por parte de los teóricos contemporáneos de la democracia participativa, como MacPherson, Poulantzas y Pateman (Ver Held, 1987:259).

5 Alusión al título del influyente libro de Boaventura Souza dos Santos (2002). 
participativa, en la medida en que recurre a los mecanismos electorales asociados a la democracia representativa (basados en el principio de un ciudadano, un voto), a la vez que coloca a los electores en el lugar de la elaboración de criterios, la deliberación y toma de decisiones políticas, asociados al proyecto democrático participativo. Con ello puede contribuir, por una parte, a subsanar los déficits de participación y representación de los regímenes representativos, a través de la activación de la ciudadanía y su politización. Esta ciudadanía más involucrada en la política puede generar presión sobre los partidos y organizaciones políticas en aras de mejorar la calidad de la representación que les otorga en las urnas. Los debates públicos en torno a los temas sometidos a consulta pueden generar nuevas perspectivas y posicionamientos que sitúen ejes políticos de articulación entre opciones políticas y ciudadanos. En relación con el proyecto democrático participativo, la consulta popular ofrece un mecanismo de participación ciudadana en el nivel de la sociedad en su conjunto, más allá del espacio de lo local donde se han dado las experiencias más exitosas del proyecto participativo hasta el presente.

$\mathrm{El}$ análisis de experiencias concretas de democracia directa, permite identificar los procesos socio-políticos que estos generan, en términos de su impacto sobre las instituciones del régimen democrático representativo y en términos de construcción de ciudadanía. En lo que sigue, analizo el referendo celebrado en Costa Rica el 7 de octubre de 2007 sobre el TLC con los Estados Unidos.

\section{CONTEXTO SOCIO-HISTÓRICO}

El 7 de octubre de 2007, Costa Rica celebró el primer referéndum de su historia. Se consultó a los ciudadanos sobre la aprobación o no del Tratado de Libre Comercio con los Estados Unidos (CAFTA-DR).

La convocatoria se dio en un contexto de polarización política. Desde el 2003 el Tratado se había ido convirtiendo gradualmente en el principal tema de debate público y de diferencia política. Mientras que la posición favorable al Tratado parecía contar con los votos necesarios para su ratificación legislativa, aún si fuera necesaria una mayoría calificada, la posición contraria se expresaba en una creciente movilización social.

El antecedente más inmediato a la convocatoria fue una multitudinaria manifestación opositora el 26 de febrero de 2007. El 12 de abril el Tribunal Supremo de Elecciones acogió la solicitud que un grupo de ciudadanos había hecho meses antes, de iniciar la recolección de firmas para convocar al referendo por iniciativa popular (TSE, Resolución 790-E-2007). Al día siguiente, el Presidente de la República, Oscar Arias Sánchez, anunció que convocaría al referendo por decreto presidencial ${ }^{6}$, a pesar de que se había opuesto en todo momento de forma contundente a una consulta popular y había señalado en reiteradas ocasiones que las elecciones de 2006 equivalían a un referendo sobre el $\mathrm{TLC}^{7}$. En el transcurso de la semana siguiente, envió el decreto de convocatoria a la Asamblea Legislativa donde fue ratificado por una abrumadora mayoría (con el apoyo, inclusive, del Partido Acción Ciudadana, el mayor partido opositor al TLC). El TSE conoció ambas solicitudes y se pronunció a favor de la iniciativa ejecutiva.

Debido a la novedad de la institución del referendo (la ley de referéndum 8492 había sido aprobada por la Asamblea Legislativa en febrero del 2006), el mismo no había sido reglamentado en el momento en que el Tribunal tomó la decisión. No fue sino hasta el 19 de junio que el Tribunal Supremo de Elecciones decretó el reglamento del referendo (TSE, decreto 11-2007) e hizo la convocatoria oficial el 12 de julio (TSE, decreto 13-2007). Durante los tres meses siguientes se dio una fuerte campaña a favor y

$6 \quad$ La ley de referendo, Ley 8492 de marzo de 2006 contempla tres vías de convocatoria a consulta: por iniciativa popular (requiere las firmas del 5\% del padrón electoral), por iniciativa del ejecutivo (requiere de un decreto ejecutivo ratificado por la Asamblea Legislativa por mayoría absoluta) y por iniciativa legislativa (requiere de mayoría legislativa calificada).

$7 \quad$ Se refería a que él había apoyado su aprobación en campaña, en tanto que el principal candidato opositor defendía la renegociación del Tratado. 
en contra del Tratado. El resultado favoreció al SI por un estrecho margen de $51,7 \%$ frente a $48,3 \%$ del NO. Participaron en los comicios el $59,4 \%$ de los ciudadanos ${ }^{8}$. Pasado el referendo quedó pendiente la aprobación de un paquete de 13 leyes que contienen las reformas legales necesarias para que el Tratado pueda entrar a regir. El Poder Ejecutivo se había opuesto a que estas leyes se incluyeran en la consulta, en la medida en que tenía interés en su aprobación más allá de un eventual rechazo del TLC. La diversidad de temas que abordan estas leyes "complementarias" al TLC, así como la magnitud de los cambios que provocan, pone en evidencia la profundidad del cambio regulatorio que implica la aprobación del Tratado para Costa Rica ${ }^{9}$.

En un horizonte temporal más amplio, el referendo se sitúa en el contexto de una transición política que se inició hace una década o un poco más ${ }^{10}$. En contraste con la historia de la segunda mitad del siglo xx, de alta participación electoral ${ }^{11}$, fuertes lealtades partidarias, baja actividad contestataria y amplio apoyo a los gobiernos; durante la última década ha caído

La participación en el referendo fue inferior a la de las elecciones nacionales de febrero de 2006, donde fueron a votar el $65,2 \%$ de los ciudadanos. Sin embargo, fue muy superior a las elecciones municipales de diciembre de 2006 donde participó el $23,8 \%$

Las leyes que tiene que cambiar o aprobar Costa Rica para que entre en vigencia el Tratado tienen que ver con la ruptura del monopolio estatal de las telecomunicaciones y los seguros, la aprobación del Tratado de UPOV en su versión más reciente, aprobación del Convenio de Budapest, eliminación de los beneficios de los representantes de casas extranjeras, aumento de los plazos de protección de patentes de medicinas y agroquímicos, aumento de la protección de patentes.

10 La definición temporal depende de si se toma como punto de inflexión el Pacto Figueres-Calderón de 1995 o las elecciones de 1998 que pusieron de manifiesto el malestar ciudadano (ver Raventós, 2008).

11 La abstención electoral entre 1962 y 1994 fue en promedio de 18\%. En 1998 aumentó a 30\%, 2002 a $31 \%$ y en 2006 al $34,5 \%$. la participación electoral de los ciudadanos, ha aumentado el malestar y la desconfianza con los políticos y los partidos, $y$ ha aumentado la movilización social (Raventós, 2008). La erosión de las lealtades partidarias ha dado lugar a gobiernos más débiles y fragmentados $y$ han aumentado las dificultades de generar acuerdos interpartidarios (Raventós et ál., 2005; Raventós, 2008a).

\section{MARCO INSTITUCIONAL: REGULACIÓN DE LA COMPETENCIA}

Sartori señala que, más que ningún otro factor, la competencia entre partidos con recursos equilibrados (políticos, humanos, económicos) es lo que genera democracia ${ }^{12}$ (Sartori citado por Zovatto y Orozco, 2008:155). En el caso de un referendo donde los protagonistas no son necesariamente los partidos (aunque pueden serlo), habría que pensar en términos de las dos posiciones en competencia y la organización que se sepan dar. Sabemos también, a partir de la crítica marxista que hace Miliband al régimen democrático representativo que esa competencia política es una competencia imperfecta (Miliband, 1976), en la medida en que entre los actores políticos hay una gran desigualdad de recursos. Los sectores poderosos, especialmente los sectores empresariales, tienen mayores recursos, no sólo económicos, sino que pueden recurrir además a la amenaza de la pérdida de confianza y la desinversión. El gobierno de la república puede usar las políticas públicas como recurso de poder. Para evitar los abusos de uno $y$ otro, las instituciones reguladoras de la competencia electoral deben desarrollar mecanismos para equilibrar la asignación de recursos, con el propósito de mejorar las condiciones de la competencia, para hacerla menos imperfecta $y$ poder generar resultados que sean percibidos como legítimos por todos los participantes, muy especialmente por parte de los perdedores.

Aquí "democracia" está referida al régimen democrático-representativo y "competencia" a la regulación de los procesos electorales. Como consecuencia, esta afirmación está sólidamente anclada dentro de la tradición demo-liberal. 
El referendo del 7 de octubre estuvo regulado por la ley 8492 aprobada por la Asamblea Legislativa, el 23 de febrero de 2006 $y$ el reglamento promulgado por el Tribunal Supremo de Elecciones, el 19 de junio de 2007. Ambas normativas señalan que se aplicará, de manera supletoria, las normas contenidas en el Código Electoral (Art. 5, Ley 8492; Art. 44 del Reglamento).

Las regulaciones del referendo y su aplicación en la consulta del 7 de octubre tuvieron continuidades $y$ cambios con respecto a la legislación que se había aplicado a la escogencia de gobernantes. Cabe destacar los siguientes temas medulares que tuvieron mayor impacto $y$ visibilidad:

1. Financiamiento estatal. Desde la promulgación del Código Electoral en 1952, el Estado contribuye de forma importante al financiamiento de las campañas políticas. La Ley y el Reglamento del Referendo son omisas en este tema. El Tribunal Supremo de Elecciones no aplicó la normativa del Código Electoral ante esta omisión, consecuencia de lo cual no destinó fondos estatales para el financiamiento de las partes en el referendo. Las campañas de las partes fueron financiadas enteramente con recursos privados.

2. En lo que se refiere al financiamiento privado, las regulaciones para evitar contribuciones grandes de actores interesados son en la práctica inexistentes en Costa Rica. Las leyes que obligan al registro de contribuciones privadas son recientes $y$ no tienen mecanismos efectivos para su cumplimiento. La Ley y Reglamento de Referendo, que formalmente reducen el monto permitido a cada contribuyente (de 40 a 20 salarios mínimos) no lo hacen en la práctica, dado que la ley permite que "cualquier persona física o jurídica", pueda aportar 20 salarios mínimos. Dada la facilidad de inscripción de sociedades, una persona física puede contribuir además varias veces desde cada una de las personas jurídicas de las que forma parte ${ }^{13}$.

3. Acceso a medios. Las regulaciones no establecen el acceso gratuito a los medios de comunicación colectiva para las partes. En esta materia coinciden el Código Electoral, la Ley de Referendo y el Reglamento de Referendo. Como consecuencia, el acceso a medios se convierte en un tema de financiamiento. El Reglamento del Referendo estipula que el Tribunal podrá usar media hora semanal gratuita en los medios de comunicación comercial.

4. Participación de autoridades estatales en la campaña. El artículo 88 del Código Electoral prohíbe explícitamente la participación de las autoridades estatales (presidente, vicepresidentes, ministros, etc.) en las campañas electorales a favor de una parte. La Ley y el Reglamento del Referendo son omisos sobre este tema, y el Tribunal permitió la participación de estas figuras, notablemente la del Presidente de la República, los vicepresidentes y los ministros de gobierno.

El artículo 88 del Código Electoral también prohíbe la participación de los funcionarios públicos durante su jornada de trabajo así como la utilización de su cargo para fines político-partidarios. La Ley de Referendo es omisa en este tema. El reglamento autorizó a los funcionarios a participar en debates así como la utilización de instalaciones públicas para este fin (artículo 24).

Los tres instrumentos jurídicos prohíben el uso de recursos públicos en la campaña de alguna de las partes. El Tribunal dio seguimiento a las denuncias de uso de recursos públicos para hacer las giras por parte del gobierno. No tomó en cuenta los ofrecimientos clientelares que hicieron autoridades públicas a favor del SI como uso de recursos públicos.

13

El reglamento del referendo introduce una novedad al hacer corresponsables a los medios de comunicación colectiva en el registro de las contribuciones privadas a través de reportes semanales de la pauta publicitaria. Esta regla puede haber significado algún avance en el registro de las contribuciones y los contribuyentes. 
5. Interlocutores del Tribunal. La Ley de Referendo es omisa en este aspecto. El reglamento de referendo, se ampara en el Código Electoral al designar a los partidos políticos como representantes de las partes. Esta decisión generó dificultades organizativas para las partes en el referendo del 7 de octubre, en la medida en que los protagonistas de ambos lados no fueron los partidos, sino que organizaciones de la sociedad civil. Por otra parte, algunos partidos, entre ellos el de gobierno, estaban divididos en el si y el NO. A esto se agrega que en ambas partes había varios partidos, que no necesariamente coordinaban entre sí. Finalmente, muchos ciudadanos sintieron violentados sus derechos al ser obligados a participar a través de los partidos y presentaron sus objeciones al Tribunal Supremo de Elecciones.

6. La Ley de Referendo introduce un importante cambio en la integración de las juntas receptoras de votos respecto de la legislación electoral. Según el Código Electoral, las mesas se integran con delegados propuestos por los partidos políticos, de tal forma que las mesas son multipartidarias y la confianza en el proceso se fundamenta en el principio de vigilancia y desconfianza mutua. La Ley del Referendo $y$ el Reglamento integran las mesas con representantes designados y remunerados por el Tribunal. Las partes sólo pueden participar a través de los partidos en calidad de fiscales, con lo cual se restringe su participación a la vigilancia del proceso (sin formar parte de él) ${ }^{14}$.

Sostendría que las normas que rigen los procesos electorales tienen la virtud de combinar vigilancia con colaboración, lo cual tiene una función incluyente de todas las fuerzas políticas. Los miembros de mesa proceden de partidos diferentes, pero trabajan juntos durante toda la jornada electoral. Durante doce horas tienen que dividir el trabajo, turnarse en asumir distintas funciones, $y$ finalmente contar los votos y levantar el acta. Este trabajo habitualmente se desarrolla en un ambiente de camaradería, lo cual no elimina el hecho de que simultáneamente hay control y vigilancia mutua.
LOS ACTORES: ORGANIZACIÓN, DISCURSOS Y PRÁCTICAS POLÍTICAS

Debido al tipo de actores en cada una de las posiciones respecto del TLC y los recursos de poder ${ }^{15}$ de los que disponían, hubo grandes diferencias en las formas de organización y las prácticas desarrolladas.

El apoyo al TLC, en adelante "el SI" estuvo organizado de forma centralizada a través de un comando de campaña y la mayor parte de sus participantes lo hicieron de forma remunerada. La dirección estuvo en manos de un ministro de gobierno que renunció a su cargo para asumir la conducción de la campaña. Los actores más visibles del SI fueron el empresariado grande, especialmente el sector exportador y el Gobierno de la República, encabezado por el Presidente, con la participación de ministros, diputados oficialistas $y$ alcaldes.

La oposición al TLC, en adelante "el NO" fue un movimiento descentralizado constituido por una gran diversidad de actores políticos y sociales que no tuvo más que una coordinación muy laxa, y se sostuvo con trabajo voluntario. Comprendió al movimiento sindical, la mayoría del movimiento cooperativo, campesino, ecologista, feminista, grupos religiosos, grupos de intelectuales y mayorías del estudiantado y profesores de las universidades estatales. Durante los meses de campaña fue coordinado por el rector de una de las universidades estatales.

En ambos casos, las alianzas y el posicionamiento público a favor o en contra del Tratado se gestaron años antes de la convocatoria a referendo. La campaña a favor del TLC empezó durante el proceso de negociación en el 2003. Durante ese año, y el siguiente, hubo una campaña financiada por el Ministerio de Comercio Exterior en los medios de comunicación colectiva y a través de vallas publicitarias en apoyo al Tratado. El núcleo de la campaña a lo largo de cinco años fue el empleo, los puestos de trabajo que dependían de las exportaciones a

15

Siguiendo a Tilly (2007:87), hay tres grandes tipos de recursos de poder político: la coerción, el capital y el compromiso. La coerción, a su vez, se puede dividir en el uso de la fuerza o la amenaza del uso de la fuerza. 
los Estados Unidos. Los negociadores recorrieron el país durante el 2004 buscando convencer a distintos grupos y comunidades de los beneficios del Tratado. En el segundo semestre del 2004, los negociadores renunciaron al gobierno de Pacheco por diferencias con el Presidente con respecto a la renuencia de este de enviar el TLC al Congreso, y trasladaron la campaña a una organización no gubernamental formada por varios de ellos, que denominaron "por Costa Rica". A la fecha se desconocen las fuentes de financiamiento de esta organización. Mantuvo presencia en la televisión y en vallas publicitarias entre 2004 y 2007. De forma menos visible, el apoyo al TLC contó durante esa fase con los salarios y el tiempo de gran cantidad de funcionarios públicos especialmente en el Ministerio de Comercio Exterior. A partir de la convocatoria al referendo el gobierno movilizó a ministros, diputados y alcaldes oficialistas a favor del Tratado, encabezados por el presidente Arias.

La oposición al TLC también se fue articulando mucho antes del referendo. Desde el inicio de la negociación del Tratado en el 2003 diversos sectores sociales habían expresado sus preocupaciones respecto a distintos aspectos. A lo largo de la negociación nuevos sectores fueron pasando a la oposición. Durante el 2004, a partir del momento en que fue divulgado el texto negociado, las universidades estatales formaron comisiones de estudio sobre el Tratado, que en la mayor parte de los casos se pronunciaron de forma crítica. También fomentaron el debate público que se canalizó en algunos casos a través de los medios de comunicación universitarios. Estos medios tienen una cobertura limitada, tanto en términos técnicos, como de audiencia, pero gozan de una gran legitimidad en la opinión pública. Se publicaron más de diez libros de editoriales académicas con contribuciones críticas al tratado. Profesionales de distintos campos recorrieron el país a solicitud de comunidades que querían informarse sobre el Tratado. Por la diversidad de temas que contiene, distintas personas se "especializaron" en distintos temas: posibles efectos de los subsidios sobre los agricultores del mercado interno, posibles efectos de las regulaciones sobre propiedad intelectual, sobre los precios de las medicinas $y$ los agroquímicos, sobre las patentes a las obtenciones vegetales, los posibles efectos de la apertura comercial sobre el empleo, los efectos sobre los precios de la apertura en telecomunicaciones, etc. En esos años hubo marchas multitudinarias - y crecientes - de oposición al Tratado (noviembre 2005, octubre 2006, febrero 2007).

Desde el 2004, el presidente Abel Pacheco, preocupado por las versiones contradictorias sobre los posibles efectos del TLC resistió enviarlo a la Asamblea Legislativa para su aprobación. A mediados del 2005, como último recurso dilatorio, convocó a cinco ciudadanos "notables" para que estudiaran el Tratado y se pronunciaran. El informe de los notables es muy crítico de los posibles efectos que puede traer el Tratado.

\section{LA CAMPAÑA DEL SI}

El presidente Arias fue la verdadera cabeza de la campaña del SI. Entre abril y octubre 2007, acudió a diversas inauguraciones de instalaciones públicas por pequeñas que fueran ${ }^{16}$, visitó las barriadas más pobres y populosas del Área Metropolitana de San José donde prometió trabajo y mejoras sociales, acudió a empresas donde habló con los trabajadores. En decenas de actividades públicas sostuvo un discurso hiperbólico sobre las bondades que esperaban al país en caso de aprobarse el TLC y los horrores que sucederían en caso de su rechazo. Esto se ilustra con las siguientes citas de su discurso en la inauguración de un parque industrial en Cartago: "los que vienen en bicicleta, con el TLC vendrán en motocicleta BMW, y los que vienen en un Hyundai, vendrán en un Mercedes Benz" (...) (LPL, 30-5-7). Como contraparte habló de que no aprobarlo sería un suicidio nacional y que rechazar al TLC convertiría el país en una réplica de Albania. Pidió a los ciudadanos que apoyaran el TLC a cambio de la realización de obra pública (en la comunidad de Osa: "Ustedes

16 En su agenda se registran visitas a comunidades donde se inaugura un centro de comunicaciones de internet con 3 ó 5 computadoras. Todas estas actividades eran aprovechadas para hablar del TLC. 
nos apoyan con el TLC $y$ nosotros les construimos un gran aeropuerto"). A pesar de este activismo electoral, Arias se negó a participar en debates públicos con dirigentes del NO.

En setiembre, un mes antes del referendo, el Semanario Universidad publicó un memorando que había sido escrito el 29 de julio por el primer Vicepresidente de la República y el diputado oficialista Fernando Sánchez, presidente de la Comisión de Reformas Electorales de la Asamblea Legislativa y primo del presidente Arias (Memorándum Casas-Sánchez). Estaba dirigido al Presidente de la República $y$ al Ministro de la Presidencia (en "asunto" detalla: "Algunas acciones urgentes para activar la campaña del SI al TLC"). El memorando constituye una fuente valiosa para conocer la racionalidad de la campaña del si y evita tener que imputar intenciones a los autores. Sus autores expresaban preocupación por la fortaleza del movimiento del No, y señalaban diversos caminos para hacer avanzar la campaña del SI. Casas y Sánchez proponían activar la coacción dentro del gobierno entre miembros del partido oficialista.

En relación con los alcaldes (ejecutivos de los gobiernos locales) planteaban:

Hay que hacerles responsables de la campaña en cada cantón y transmitirles, con toda crudeza, una idea muy simple: el alcalde que no gana su cantón el 7 de octubre no va a recibir un cinco (centavo) del gobierno en los próximos 3 años, (en tanto que a los regidores municipales del oficialismo) (...) hay que recordarles sus aspiraciones personales: de ganar el referéndum depende que tengan posibilidades reales de seguir siendo regidores 0 de llegar a ser alcaldes o diputados (...) el que no se mete de lleno se 'quema'.

Por otra parte, sugerían una campaña de estímulo del miedo:

Ese miedo es de cuatro tipos:

i. Miedo a la pérdida del empleo. (...)

ii. Miedo al ataque a las instituciones democráticas. Es crucial convertir al SI en equivalente con la democracia $y$ la institucionalidad
(...) y al No en equivalente de la violencia y la deslealtad con la democracia. Hay que entender una cosa: nadie está dispuesto a "morir" por el libre comercio pero tal vez sí por la democracia (...).

iii. Miedo a la injerencia extranjera en el NO. Hay que restregar por todas partes la conexión del NO con Fidel, Chávez y Ortega en términos bastante estridentes (...).

iv. Miedo al efecto de un triunfo del No sobre el Gobierno. (...) Mucha gente simplemente no ha hecho la conexión de que un triunfo del NO en el referéndum dejará al Gobierno en una situación precaria, (...) y al país en una situación de ingobernabilidad. Esa conexión hay que inducirla.

Proponían en el memorando que altos funcionarios públicos visitaran empresas para hacer campaña a favor del SI, ocultándolas con otros motivos.

Que la empresa envíe de inmediato una carta al Ministerio de Planificación pidiendo que el gobierno le envíe un representante para hablar del Plan Nacional de Desarrollo o de la visión futura del país o algo por el estilo (eso para cubrirnos las espaldas de cara al TSE).

Finalmente, proponían incrementar la campaña televisiva "no hay que tener pudor alguno en saturar los medios de comunicación con publicidad" y generar una campaña negativa respecto de los dirigentes de la campaña del No, sobre sus motivos, métodos y vínculos internacionales. El memorando constituye una buena descripción de lo que fue la campaña del SI, el hecho de que haya sido divulgado exime de imputar intenciones a los actores, en la medida en que las reconocen explícitamente ${ }^{17}$.

A la campaña del Gobierno se agregó la participación activa del embajador de EE.UU.

El vice-presidente Casas renunció producto del escándalo. El diputado Sánchez se mantuvo en su cargo, a pesar de la presión constante de grupos de electores que siguen solicitando su renuncia. Como gesto simbólico, renunció a la comisión de reformas electorales. 
Dio declaraciones a favor de la ratificación del Tratado y participó en actividades de campaña de forma tan ostensible, que después del referendo discretamente fue relevado de su cargo por su gobierno.

La campaña en medios comerciales y en la televisión estatal fue en la práctica dominio del SI que tenía los recursos para pagarla. Mientras el NO pautó 125 anuncios, los del SI ascendieron a 1319 (Cortés, 2008). En los últimos tres días antes del referendo, en los que la ley establece una tregua que prohíbe la propaganda, un canal de televisión pasó decenas de veces una "noticia" de CNN en Español en la que Ricardo Ernst, experto de la Escuela de Negocios de la Universidad de Georgetown señalaba que si no se aprobaba el TLC "el barco del progreso" pasaría "de largo de Costa Rica".

En síntesis, la campaña del sI articuló una poderosa combinación de recursos de poder: grandes cantidades de dinero que aseguraron el acceso irrestricto a los medios de comunicación colectiva combinado con la promesa de empleo y un futuro mejor, así como obra pública, con la participación protagónica del Presidente de la República.

\section{LA CAMPAÑA DEL NO}

La oposición al TLC tenía un alto nivel de movilización en el momento de la convocatoria a referendo, $y$ esta les sorprendión ${ }^{18}$, por lo que el inicio de la campaña estuvo marcado por mucha confusión y conflicto interno. Importantes sectores de la dirigencia del NO estaba convencida que el TLC sería declarado inconstitucional por la Sala Constitucional, por lo que se concentraron en presionar para que la Sala conociera el Tratado y se pronunciara. También, el referendo significaba pasar de la lucha en "la calle" a la lucha por los votos. Este

Desde el año 2004 algunos sectores opositores al TLC había planteado que el futuro del TLC debía dirimirse en una consulta popular. Sin embargo, una vez que se aprobó la ley de referendo, parecía ser que este no se podía aplicar al TLC dado que tenía implicaciones fiscales, tema que está vedado para este tipo de consultas. cambio generaba ambivalencia y diferencias de criterio en el movimiento del No. Las elecciones son la principal forma $y$ la más legitimada de participación política en Costa Rica, por lo que negarse a participar era difícil. A esto se sumaba la molestia por la decisión del Tribunal de aceptar el referendo por decreto presidencial, a la vez que había desconfianza respecto de las posibilidades de que fuera a haber condiciones de equidad en la competencia para las partes.

Pasada esta primera fase, la mayor parte de los activistas y dirigentes del NO se lanzó con entusiasmo a trabajar por el triunfo en el referendo. Ante la ausencia de recursos económicos para acceder a los medios de comunicación colectiva, se desarrolló la estrategia de hacer campaña "casa por casa" y la promoción de la organización de las comunidades en "comités patrióticos", que se hicieron cargo de las visitas a las casas, el proselitismo electoral, la fiscalización y la logística del 7 de febrero. Según distintos cálculos llegó a haber entre 150 y 180 comités patrióticos distribuidos en todo el territorio nacional.

La propaganda que fue repartida casa por casa fue financiada por las organizaciones sociales con recursos propios, especialmente los sindicatos $y$ en muchos casos por los mismos activistas del NO, entre quienes hubo la participación activa de sectores medios con alguna capacidad económica. Hubo además una campaña de recaudación de fondos denominada "El NO lo financio yo" que tuvo sin embargo alcances limitados. La organización de los comités patrióticos llevó a la formación de redes de confianza interpersonal entre vecinos de una comunidad que se constituyeron en un recurso político importante.

Sin lugar a dudas el mayor recurso de poder del NO estuvo dado por el compromiso de un conjunto de personas y organizaciones políticamente muy diversos. Su diversidad se expresó también en la multiplicidad de motivos $y$ argumentos para oponerse al Tratado ${ }^{19}$. El compromiso llevó a centenares de activistas a

19 No obstante, a pesar de esta diversidad de motivos hubo claros ejes articuladores como fue, centralmente, la defensa del estado social de derecho. 
dedicar tiempo libre y recursos personales a la campaña, a convencer a otros, en conversaciones interpersonales y debates públicos. La propaganda fue fundamentalmente en la forma de volantes. En lugar de vallas publicitarias, activistas del No colocaron leyendas en sus casas.

En términos organizativos, la campaña del NO se caracterizó por una red extraordinariamente diversa, escasamente articulada. Esta diversidad generó conflictos y dificultades operativas en el plano de la coordinación nacional $y$ en su participación como parte en la organización central. Esto se expresó con claridad en tareas en que "el No" tenía que presentarse como un actor unitario cuando en la realidad se trataba de muchos actores muy diversos entre sí. Un ejemplo que ilustra estos conflictos fueron las disputas en torno a la definición de los participantes del NO en los debates televisados entre el si y el No ¿Quién hablaría en nombre del NO? ¿Quién estaba autorizado a definir quién hablaba en nombre del NO? ¿Cuál de las posiciones de oposición sería la posición "oficial" del no en el debate?

La desconfianza ${ }^{20}$ respecto de la imparcialidad del Tribunal Supremo de Elecciones por parte del movimiento del No llevó a la organización de un programa nacional de reclutamiento y capacitación de fiscales, de tal forma que la mayor parte de las mesas electorales estuvo vigilada por al menos un fiscal del No. En el Área Metropolitana la mayor parte de las juntas receptoras tuvo dos o tres fiscales.

Pasado el referendo, hubo dos reuniones del movimiento del no (una de ellas masiva) en que se decidió por aclamación rechazar los resultados del referendo. Acusaron al Tribunal de haber permitido la violación de la tregua ${ }^{21}$

Esta desconfianza se fundamentaba en parte de que en las elecciones de 2006 hubo denuncias de irregularidades en cientos de mesas electorales. En un país donde la pureza del sufragio ha sido un valor cívico supremo, las denuncias del 2006 tuvieron un fuerte impacto. A esto se agrega que las denuncias procedieron de la oposición política, de donde provenían la mayor parte de los activistas del NO.

21 El artículo 24 del Reglamento del Referendo establece: De conformidad con el artículo 85 inciso g) del Código Electoral, durante los dos días inmedia- de tres días a través de pseudo-noticias que influyeron la opinión pública, y lanzaron acusación de "fraude mediático".

\section{REFLEXIONES FINALES: REFERENDO Y DEMOCRACIA}

Para concluir, propongo respuestas tentativas a las preguntas planteadas al inicio de este artículo.

¿Contribuyen los referendos al debilitamiento de los terrenos de mediación política donde se dan la deliberación y negociación inter-partidaria? En este mismo sentido ¿contribuyen al debilitamiento de los partidos?

Uno de los riesgos que se le han imputado a los procesos de democracia directa, es el de debilitamiento de las instituciones de mediación política - especialmente los partidos políticos-y el desarrollo de tendencias plebiscitarias, incluido el costo que pueden tener estos procesos para las formas de deliberación y negociación políticas. Cuando se convocó a referendo, el TLC se encontraba desde hacía más de un año en la Asamblea Legislativa. No obstante, esto no significa que haya habido espacio para negociación y deliberación política. Por ser un Tratado, firmado por los países signatarios, el poder legislativo no puede introducir cambios de ningún tipo ("no se le puede cambiar ni una coma") ${ }^{22}$. Los partidos favorables a la aprobación constituyeron un bloque de 38 diputados, encabezados por el partido de gobierno, a quienes la oposición denominó G38 o "mayoría mecánica" en referencia a su total

tos anteriores y el día del referéndum, no podrá difundirse propaganda de ninguna especie relativa al proyecto objeto de consulta. No obstante, hubo durante esos días una intensa publicidad a favor del SI disfrazada de noticias, que fue caracterizada de "fraude mediático" en el balance del NO.

22 Esta situación también se dio con la aprobación de los programas de ajuste estructural entre 1985 y 1995 (Raventós, 1995). Tengo la duda de si esta restricción es legal y absoluta o si es un recurso de poder del Ejecutivo para limitar el debate legislativo. 
falta de disposición a entrar a debatir y deliberar sobre la conveniencia del Tratado y -llegado el momento- su disposición a votar de forma mecánica lo estipulado. Entre mayo y diciembre de 2006 los partidos opositores al Tratado convocaron a representantes de distintos sectores que se oponían y presentaron, en forma argumentativa, los perjuicios que consideraban que traería el TLC al país. Como respuesta, los miembros del G38 guardaban silencio y esperaban el momento de las votaciones para desechar las propuestas opositoras. En este encuadre institucional, presentar objeciones o críticas se convertía en una pérdida de tiempo. El 12 de diciembre de 2006, los representantes del G38 en la comisión forzaron la votación y aprobaron el tratado.

En síntesis, la Asamblea Legislativa no ejerció las funciones deliberativas, ni abrió la negociación política. Como consecuencia, este espacio de mediación no cumplió con las funciones de mediación que le asigna la teoría democrática. Más allá del espacio legislativo, hubo otras oportunidades de negociación interpartidaria, una de ellas cuando se reunieron Oscar Arias y Ottón Solís a principios del 2006, el primero como presidente electo y el segundo como candidato perdedor $y$ dirigente del partido con la segunda minoría legislativa. En la reunión, Solís planteó a Arias la posibilidad de renegociar el TLC respecto de los temas más conflictivos. Arias respondió que era más fácil cambiar los diez mandamientos que el TLC. Cerró así la posibilidad de una renegociación externa y no hizo propuesta alternativa de negociación interna ${ }^{23}$.

En síntesis, ni el parlamento, ni los partidos, ni los dirigentes de estos, abrieron procesos de negociación conducentes a una superación de las diferencias provocadas por el TLC antes de la convocatoria al referendo. En otras palabras, las

23 Anteriormente, miembros del PLN habían sugerido que quizás se podía hacer una negociación interna que contribuyera a paliar los efectos sociales regresivos que tienen los tratados de libre comercio. Un ejemplo de lo anterior fue la propuesta hecha en el 2005 por el Ministro de Educación de la administración Arias, Leonardo Garnier, de la negociación del TLC a cambio de un pacto fiscal progresivo. instancias de mediación política no se constituyeron en espacios de deliberación y negociación. A pesar de que las minorías mostraron esta disposición, las mayorías no lo permitieron. Como consecuencia, la debilidad de las mediaciones no se origina en el referendo sino que internamente en las instancias representativas.

Por otra parte, el Reglamento del Referendo designa a los partidos políticos como el vínculo de las posiciones en disputa con el Tribunal Supremo de Elecciones ${ }^{24}$, por lo que no les menoscaba, en el plano reglamentario, su lugar de mediación política. El referendo del 7 de octubre, supuso una oportunidad de constituir alianzas de partidos para encabezar tanto la campaña del si como la del NO. Sin embargo, como evidencia el análisis de las campañas, estas organizaciones tuvieron una participación muy disminuida $y$ fueron desbordados por el gobierno y la sociedad civil. Diversos motivos explican la debilidad partidaria. Una de ellas fue que tanto el si como el No tenían en su seno varios partidos. A esto se agrega que el partido de gobierno tenía fracturas internas con respecto al TLC: el gobierno y el directorio político del PLN estaban con el SI, otro sector de la dirigencia formó la agrupación "Liberacionistas por el NO". A esto se agrega lo novedoso del proceso y la brevedad de los plazos, que condujeron a que los procesos de articulación de los partidos alrededor de las posiciones de la consulta fueron limitados. En tercer lugar, entre las organizaciones sociales que surgieron en la campaña del No había algunas con fuertes actitudes anti-partidistas. Estas se expresaron en el malestar con el reglamento del referendo que definió a los partidos como los interlocutores del Tribunal para las tareas de fiscalización el día de las votaciones. Así, a pesar de que el formato institucional asigna a los partidos el lugar de la mediación, esta fue en la práctica muy débil por razones políticas (el desprestigio de los partidos) y por la debilidad institucional de estos. Su papel se restringió al envío de las

24 El reglamento otorga a los partidos políticos el monopolio de la fiscalización de los comicios. La sociedad civil se ve limitada al lugar de "observadora", sin potestades fiscalizadoras. 
listas de los fiscales al Tribunal Supremo de Elecciones. En muchos casos, las listas fueron construidas y remitidas a los partidos por otras organizaciones, quienes luego cumplieron con enviarlas al Tribunal.

El único partido que salió fortalecido del proceso de referendo fue el partido de gobierno, el Partido Liberación Nacional. Este fortalecimiento está estrechamente asociado a los rasgos plebiscitarios que tuvo la intervención del presidente Arias en la campaña y la activación que hizo de relaciones clientelares. Este tipo de participación ha sido común en la historia política costarricense: los partidos se fortalecen en y a través del gobierno (Estado de la Nación, 2001) a través de los recursos de poder que les da esta posición, más que en la lucha política. La vida partidaria ha sido, en buena medida, la vida de los partidos en el gobierno. Esta forma de intervención de los partidos es vertical y poco democrática, usa el dinero y la coacción a cambio de votos de los sectores vulnerables.

En síntesis, la debilidad de los partidos, de sus capacidades deliberativas y de negociación no es atribuible al referendo, sino que es un rasgo previo a este. El referendo ofreció a los partidos una oportunidad de crear articulaciones y colaboraciones políticas que no fue aprovechada por estos.

¿Acentúan las consultas populares los rasgos plebiscitarios de tal forma que la consulta se convierte en una aprobación o rechazo del jefe de estado? ¿Contribuyen al fortalecimiento de liderazgos carismáticos?

La ley que regula el referendo contempla la convocatoria a referendo por iniciativa presidencial $^{25}$. Esta vía ha sido señalada como un medio a través del cual presidentes en ejercicio usan este instrumento de participación ciudadana para fortalecer su poder y con frecuencia lo

Algunos de los países con mayor tradición de democracia directa — como Suiza y Uruguayreservan la convocatoria a referendo a la iniciativa popular. Esta norma se fundamenta en que el poder ejecutivo $y$ legislativo tienen otros recursos para legislar. convierten en un evento plebiscitario (Lissidini, 2007). En el caso del referendo del 7 de octubre, la normativa permitió al presidente Arias realizar la convocatoria, cuando a lo largo de varios años se había opuesto a que la decisión con respecto al TLC se dirimiera de esta forma. Por otra parte, privó a los ciudadanos de hacer la consulta por iniciativa popular.

Más allá de su decisión en la convocatoria, el Tribunal Supremo de Elecciones, con base en la interpretación que hizo de la normativa, permitió la participación activa del presidente Arias en la campaña, en los términos reseñados arriba. El Presidente no sólo defendió el Tratado de forma demagógica, sino que también hizo uso de su posición oficial para hacer ofertas clientelares.

Estos dos aspectos evidencian limitaciones de esta experiencia de referendo en tanto posibilitó el recurso a apelaciones plebiscitarias por parte del presidente Arias. Este factor fue decisivo para una quinta parte de los votantes del SI. Según un sondeo telefónico realizado por la Universidad de Costa Rica inmediatamente después del referendo, veinte por ciento de los votantes del si decidió su voto a partir de la posición del Presidente, de lo cual se desprende que si bien la campaña de Arias no tuvo el impacto de otros liderazgos que hacen apelaciones plebiscitarias, puede considerarse que su participación en este terreno fue decisiva para el resultado.

¿Hubo un equilibrio de los recursos de las partes para asegurar la legitimidad de los resultados?

Como se evidenció en el apartado correspondiente, hubo graves deficiencias en la regulación de la competencia al no asegurar financiamiento público para las partes, y sobre todo, al no asegurar un espacio equitativo en los medios de comunicación colectiva. El haber permitido que el Presidente, ministros, diputados y alcaldes participaran activamente en la campaña, incluso con ofrecimientos clientelares no asociados a los potenciales beneficios del Tratado, fue una importante falla en la acción del Tribunal. En estos aspectos, la reglamentación del referendo significó un retroceso con 
respecto a las normas que rigen las elecciones nacionales. La regulación de los medios, en términos de su intervención con propaganda velada, es una tarea impostergable para el Tribunal. En este sentido, $y$ retomando el planteamiento de Sartori, la institucionalidad electoral no generó las condiciones mínimas de equidad para que la competencia fuera aceptable para las partes. Como consecuencia, los perdedores de la contienda no aceptaron los resultados y el Tribunal perdió legitimidad en el proceso, al asociársele con los sectores ganadores ${ }^{26}$. Esta primera experiencia de referendo obliga a la reflexión $y$ a la necesidad de regulaciones efectivas para equilibrar los recursos de las partes. Urge limitar y transparentar el financiamiento privado, a la vez que generar mecanismos para asegurar el acceso - lo más equitativo posible- de las partes a los medios, especialmente la televisión. El único espacio televisivo en el que tuvieron un acceso paritario ambas partes, el de los debates, fue muy valorado por la ciudadanía, especialmente por los votantes, tanto los del si como los del No. Un ejemplo internacional de suma importancia es la reforma promulgada recientemente por el IFE en México, con la cual se prohíbe la publicidad pagada en la televisión. Esta medida contribuye a garantizar el acceso a este medio y a disminuir los riesgos de la colonización de la política por parte de las empresas y sectores acaudalados.

¿Generó el referendo procesos de participación y control por parte de la ciudadanía?

El referendo generó procesos de activación ciudadana y participación muy extendidos. La convocatoria a referendo colocó esta decisión en un terreno socialmente conocido, aceptado y respetado por parte de todos los actores involucrados. El fuerte arraigo cultural que tienen las elecciones en Costa Rica permitió a

Según el sondeo post-referendo realizado por la Universidad de Costa Rica, sólo un tercio de los votantes del NO consideró independientes las posiciones del Tribunal Electoral. Al preguntárseles quiénes habían influido al Tribunal, más de la mitad señaló al presidente Arias $(53,4 \%)$ y poco más de un tercio a "los del SI" (34,6\%). los actores canalizar sus energías para ganar la elección. Generó debate y con ello un enriquecimiento y ensanchamiento del espacio público y procesos de politización de la ciudadanía. A pesar de esto, $y$ posiblemente por ser la primera experiencia de este tipo, en una cultura política poco deliberativa, los resultados de los debates fueron pobres en términos argumentativos: en la mayor parte de los temas, se trató más bien de discursos paralelos que no entraron en diálogo. A pesar de lo anterior, hubo recepción entusiasta de esta forma de hacer política por parte de amplios sectores de la ciudadanía y los argumentos esgrimidos por las partes fueron tomados en cuenta en los procesos de elaboración de las posiciones de los ciudadanos y en su decisión de voto. Esta activación ciudadana se concentró particularmente en la campaña del No, sin embargo, también se expresa, aunque en menor medida, en los votantes del SI.

La formación de los comités patrióticos fue posiblemente la principal innovación democrática del proceso de referendo. Muchos siguen organizados un año después, otros no se reúnen ya, pero sus miembros se sienten parte de la redes que se crearon en ese momento. En todos se expresa una búsqueda de nuevas formas de participación e incidencia política.

Al principio de este artículo, argumenté que es necesario incluir los aportes de la democracia participativa para evaluar los procesos de democracia directa. La construcción de ciudadanía que se dio a través de la participación, la elaboración de posiciones y en general la politización, se subraya a través de la incorporación de las contribuciones de esta vertiente teórica. Una ciudadanía más activa, más dispuesta a participar políticamente puede ser un camino hacia la revitalización de las democracias latinoamericanas y hacia la limitación de sus rasgos delegativos.

El Programa Nacional de Fiscales del movimiento del NO es una experiencia interesante en términos de construcción democrática. Es una intervención que busca subsanar la desconfianza de activistas del NO respecto de la imparcialidad del Tribunal a través de la fiscalización en las urnas. Este hecho es especialmente importante en el contexto de algunos hechos 
significativos de la última década. A partir de 1998, la participación de los partidos políticos ha sido cada vez más débil en los procesos electorales; al extremo que desde el año 2002 el Tribunal se ha visto obligado a nombrar miembros de mesa para suplir la ausencia de delegados partidarios, situación que se repitió en 2006. Las denuncias de irregularidades electorales en cientos de meses en el 2006 evidenciaron que en muchas juntas receptoras no hubo miembros designados de los partidos, elemento fundamental para garantizar la transparencia y legitimidad del proceso. En este sentido, la organización de un programa nacional de fiscales dentro del movimiento del NO, se inserta en la tradición electoral en la cultura política costarricense. Aquí los actores recurren a un mecanismo que conduce al fortalecimiento de la institucionalidad electoral.

Otro aporte de la democracia directa puede estar asociado a la politización que provocó el referendo sobre el TLC, que hizo emerger esbozos de un proyecto político post-neoliberal, lo cual no suele darse en las campañas electorales presidenciales, donde el interés de los actores por ganar las elecciones, los lleva a abordar de forma superficial sus diferencias políticas. El debate político diferenciado de la elección de personas (como sucede en las elecciones presidenciales) puede ser un aporte de la democracia directa a la democracia.

El proceso de referendo activó políticamente a amplios sectores de la ciudadanía, incrementando su interés por la política y su participación, más allá de las elecciones de gobernantes de cada cuatro años. El TLC involucraba múltiples temas sobre el tipo de sociedad, el papel del Estado, los derechos de distintos actores, las relaciones con los Estados Unidos y las formas de distribución deseables, cuya discusión provocó amplios procesos de politización ciudadana. Sin embargo, esto es solo parte de la historia, dado que la alta abstención abre preguntas sobre quiénes se abstuvieron y por qué. Si se tiene en cuenta que no votó el $40 \%$ de quienes podían hacerlo, es importante tratar de entender si existen diferencias sociales sistemáticas entre votantes y abstencionistas. Otras investigaciones específicas sobre este tema tendrán que responder estas preguntas.
El balance del referendo a la luz de las teorías de la democracia muestra una de cal y una de arena. Por una parte, la activación política de amplios sectores de la ciudadanía abre esperanzas sobre la formación de nuevos sujetos políticos cuya participación pueda revitalizar la democracia. Por otro, el proceso de aprobación del TLC, antes y durante el referendo, mostró las profundas limitaciones del actual régimen de democracia representativa en Costa Rica: partidos débiles, incapacidad de negociación, de construir acuerdos políticos y de articular las relaciones con la ciudadanía. También la institución que arbitra los procesos electorales, el Tribunal Supremo de Elecciones salió debilitado del proceso, debido a su incapacidad de regular la competencia para permitir una cierta equiparación de recursos. El referendo se dirimió en una extrema desigualdad de recursos, en tanto que el si tuvo el capital y la coacción, el No solo tuvo acceso al compromiso de sus participantes.

\section{BIBLIOGRAFÍA CITADA}

Cortés Ramos, Alberto. "Los límites del referendo sobre el TLC como instrumento de participación política en Costa Rica”. Ponencia presentada al Congreso de la Asociación Latinoamericana de Ciencias Políticas (ALACIP). 2008.

Dagnino, Olvera y Panfichi (coords.). La disputa por la construcción democrática en América Latina. Mexico: Fondo de Cultura Económica, CIESAS. Universidad Veracruzana, 2006.

Estado de la Nación. Auditoría de la calidad de la democracia en Costa Rica. Programa de Estado de la Nación. San José, Costa Rica, 2001.

Held, David. Models of Democracy. California: Stanford University Press, 1987.

Hernández, Gerardo. "Óscar Arias: liderazgo, poder y contextos políticos”. Ponencia presentada en Coloquio Internacional 
sobre liderazgo político en sociedades modernas. México: Colegio de Veracruz, 12-15 de noviembre. 2007.

Lissidini, Alicia. "Democracia directa y gobernanza: los desafíos de las consultas populares en Latinoamérica”. Propuesta de panel para el área temática nro. 3: Ciudadanía y ejercicio de la representación política. Costa Rica: Congreso de la Asociación Latinoamericana de Ciencias Políticas, 2008.

López, Luis Paulino. "El Tribunal Supremo de Elecciones en el proceso electoral 2006. Entre la tradición y el cuestionamiento". Documento inédito. Instituto de Investigaciones Sociales. Universidad de Costa Rica, 2008.

Miliband, Ralph. El Estado en la sociedad capitalista. México: Siglo XXI Editores, 1976.

O’Donnell . "Delegative democracy?". Journal of Democracy 5 (1). 1994: 3-56.

Pateman, Carole. Participation and Democratic Theory. Cambridge: Cambridge University Press, 1970.

Raventós, Ciska. "The construction of an order: structural adjustment in Costa Rica. 1985-1995". [Tesis doctoral]. New School for Social Research, 1995.

"Lo que fue ya no es, y lo nuevo aún no toma forma: elecciones 2006 en perspectiva histórica". América Latina Hoy 49. 2008a.

. "Cultura política y participación". Documento inédito. Instituto de Investigaciones Sociales. Universidad de Costa Rica, 2008b.

Raventós Vorst Ciska; Fournier Facio, Marco Vinicio; Ramírez Moreira, Olman;
Gutiérrez Espeleta, Ana Lucía; García Fernández, Jorge Raúl. Abstencionistas en Costa Rica: ¿quiénes son y por qué no votan? San José: Editorial de la Universidad de Costa Rica, 2005.

Santos, Boaventura de Souza (coord.). Democratizar a Democracia: os caminos de democracia participativa. Río de Janeiro: Civilización Brasileira, 2002.

Zovatto, Daniel; Orozco Henríquez, J. Jesús. "Reforma política y electoral en América Latina 1978-2007: lectura regional comparada". Zovatto, Orozco. Reforma política y electoral en América Latina 1978-2007. México: Coedición IDEA-UNAM, 2008.

Zovatto, Daniel. "La financiación de la política en Iberoamérica: una visión preliminar comparada”. Del Castillo, Pilar; Zovatto, Daniel (editores). La financiación de la politica en Iberoamérica. San José: IIDHCAPEL.

\section{LEGISLACIÓN}

República de Costa Rica. Código Electoral. Ley 1536. 1952.

República de Costa Rica. Ley sobre regulación del referendo. Ley 8492. 2006.

República de Costa Rica. Reglamento para los procesos de referendo. Decreto 11. 2007.

\section{ENCUESTAS}

Instituto de Investigaciones Sociales. Encuesta Nacional sobre Abstencionismo. 2003.

Instituto de Investigaciones Sociales. Encuesta Nacional de Participación en la Politica y las Elecciones. 2007.

Instituto de Investigaciones Sociales, Centro de Opinión Pública, Escuela de Estadística. 
Sondeo telefónico postelectoral. Febrero 2006.

Instituto de Investigaciones Sociales, Escuela de Estadística. Sondeo telefónico postreferendo. Octubre 2007.
ENTREVISTAS

Entrevista a Elizabeth Fonseca, diputada del Partido Acción Ciudadana.

Entrevista a Jorge Coronado, miembro del equipo coordinador de la Coordinadora Nacional de Lucha contra el TLC. 
